Session 2793

\title{
Developing an Outcomes Assessment Survey for Seniors, Alumni and Managers/Supervisors
}

\author{
Robert J. Gustafson, John A. Merrill \\ The Ohio State University
}

\section{Introduction}

During the 1998-99 Academic year the Outcomes Assessment Committee (OAC) for Undergraduate Engineering Programs at The Ohio State University developed a Programs Outcomes Assessment Model. In the model, collection of data from constituents (e.g. current students, alumni, and employers) is important to both the Program Educational Objectives System (long-term) and the Programs Outcomes System (short-term). The OAC developed a series of surveys to seek data on the perceived importance of outcomes and objectives established for our current engineering programs and assess how well each program is doing relative to its objectives. The surveys are intended to be an integral part of the data collected for program outcomes assessment including items directly relevant to the ABET EC2000 criteria. However, the results must be combined with other outcomes assessment information collected by the College and its programs to support a plan of action for continuous improvement at each level.

This paper will briefly outline the process for survey development, the components of the survey and then summarize the data from the first year of use. Generally the data in this report is an aggregate over all programs of the College. Since differences in responses between programs can exist and programs have additional inputs from other sources, this information needs to be used carefully by each program as part of their on-going outcomes assessment and continuous quality improvement. In some cases observations about the data will be included to enhance understanding. Recommendations for future survey development and follow-up are being developed by OAC and the individual programs.

\section{Selection of Survey Groups}

The OAC decided to focus on three groups: 1) exiting seniors, 2) recent alumni, and 3) managers/supervisors of our alumni. Alumni two and six years after graduation were selected with the idea that they would still have a connection to the programs as currently offered. In our assessment model, employers were a significant constituent group. In the Committee's opinion, Supervisors and Managers for our recent alumni would be in a position to comment on both the importance of an outcome/objective to engineering practice and the ability/preparation of our recent graduates. On a trial basis and as a strategy to approach this supervisor group, the fifteenth year alumni of the College were selected as a population to represent managers and supervisors of the recent alumni. 


\section{Surveys Developed}

\section{Alumni survey}

After review of available surveys from other institutions and consultation with faculty from our campus with survey expertise, a five-part alumni survey was developed (See Appendix). Each part is described briefly in the following paragraphs.

Part I. Educational Outcomes - General: This segment focused on the ABET EC2000 Criterion 3 Program Outcomes and Assessment. Alumni were asked to rate twenty-five skills, abilities and attributes generally expected of an engineering graduate in two ways. First, they were asked how important each has been relative to their needs and employment experience since graduation. Second, they were asked to rate each item relative to their abilities. Response for Importance was divided into a five segment Lickert scale. For scoring they were weighted: Not Important $=1$, Somewhat Important $=2$, Important $=3$, Very important $=4$, Extremely Important $=5$. Similarly Ability on the job was rated and scored; Not Prepared $=1$, Somewhat Prepared $=2$, Prepared $=3$, Well Prepared $=4$, Very Well Prepared $=5$. A final question related to being a licensed professional was included.

Part II. Educational Experience at Ohio State: This section focused on the quality of instruction received at The Ohio State University. Alumni were asked to respond to twenty-five questions related to quality of instruction, advising and facilities. Responses were again scored on a Lickert scale with the following options: Unsatisfactory $=1$, Poor $=2$, Fair $=3$, Good $=4$ Excellent $=5$ or no opinion (not included in analysis). In addition five questions regarding overall preparation were asked using the same available response scale.

Part III. Program Specific Section: In this section each program was afforded the opportunity to focus on ABET EC 2000 Criterion 2 Program Educational Objectives and any other program specific information they desired to collect. Format was specified by the Program. Data from this section was summarized by the Program.

Part IV. Additional Comments and Suggestions: This segment simply solicited comments regarding the program or educational experiences at Ohio State. Suggestions for improvement were specifically requested to be forwarded to the individual program.

Part V. Background/Demographic Information: This segment collected twelve items of demographic data about the respondent.

\section{Engineering Supervisor Assessment Survey}

A survey for use with fifteenth year alumni, as a surrogate for supervisors, was developed in three parts. The first part of the survey simply asked for the primary job functions of the person being surveyed. The second segment was a slightly modified version of Part I of the Alumni Survey on Skills, Abilities and Attributes. The respondent was asked to rate Importance in regard to a new engineer joining the firm. Rather than Ability, the respondent was asked to rate Preparation of recent Ohio State engineering graduates that they supervise. Respondents were 
asked to indicate the program of the person(s) on which they were basing their evaluation. They were asked to do multiple forms if more than one program was represented. If the respondent was not supervising any recent graduates, they were still asked to respond to the importance questions. The last element of the survey asked for additional comments regarding the graduates and suggestions for survey improvement.

\section{Senior Exit Survey}

A four part, Senior Exit Survey was developed by the OAC. The intent was for the survey to be administered to seniors at or nearing graduation. Part I asked for seven items related to demographics, participation in various programs, and future plans. Part II - Educational Outcomes - General used the same elements and structure as Part I of the Alumni Survey. Students were asked to rate Importance of each item and their current Ability. Part III Educational Experience at Ohio State made use of the same structure as Part II of the Alumni Survey with the addition of two questions related to Coop/Intern and Career Services. Since the survey form was not finalized until end of winter quarter 1998, spring quarter 1999 graduates were generally the only ones available for this survey. As with the all surveys, use by each Department/Program was at the discretion of the program.

\section{Populations Surveyed and Return Data}

For the Alumni and Supervisor/Manager Surveys (Years 2, 6, \& 15), available addresses from the OSU Alumni Association were used. Alumni graduates were based on calendar year; Year 2 $=1996$, Year $6=1992$, and Year $15=1983$. The Table below indicates the number of surveys sent out in January of 1999, and number returned. For the Senior Exit Survey, seven programs across five Departments used all or a portion of the survey. The number of students surveyed is indicated in the Table below. Some programs choose to continue using existing survey forms and procedures, rather than adopt the form at this time.

\begin{tabular}{|l|c|c|c|c|c|c|c|c|}
\hline \multicolumn{2}{|c|}{ Table 1. Surveys Distributed and Returned } \\
\hline & $\begin{array}{c}\text { Exits } \\
\text { Yr 0 - 99 }\end{array}$ & \multicolumn{2}{|c|}{ AlumniYr 2-96 } & \multicolumn{2}{|c|}{ AlumniYr 6-92 } & \multicolumn{3}{|c|}{$\begin{array}{l}\text { Supervisor } \\
\text { Yr 15 - 83 }\end{array}$} \\
\hline Program & Used $^{(2)}$ & Sent & Retnd & Sent & Retnd & Sent & Retnd & Grad (1) \\
\hline Total & 147 & 743 & 102 & 675 & 138 & 961 & 121 & $\begin{array}{c}49 \\
(40.5 \%)\end{array}$ \\
\hline Percent Returned & --------- & ------- & $13.7 \%$ & ------ & $20.4 \%$ & ------ & $12.5 \%$ & $5.1 \%$ \\
\hline
\end{tabular}

(1) Not all respondents commented on both Importance and Graduate Preparation. This column gives number responding to graduate preparation.

(2) Not all programs used all elements of survey.

\section{Overview Analysis of Data on Respondents}

Background data collected from the respondents was aggregated across the college and presented in detail in a Report of the OAC to the faculty of the College. In summary, distribution of respondents showed the respondents to be generally representative of the population of graduates at large in terms of gender, ethnicity, and citizenship. As an example of results, employment description showed full-time employment for 92\% of Yr 2 and 97\% of Yr 6 alumni with 76\% and $80 \%$ reporting themselves as employed in engineering. Most frequently reported primary 
job functions for Yr 2 and Yr 6 alumni were design, project engineering, and management. Primary job functions for Yr 15 alumni were management, project engineer, manufacturing, and research and development. Ten percent of $\operatorname{Yr} 2$ and $6 \%$ of $\operatorname{Yr} 6$ alumni reported working outside of the U.S.

\section{Educational Outcomes Summary}

Since the same twenty-five Educational Outcomes questions were asked of all four groups, a summary across the groups can be presented. Only a few questions showed obvious variation or trends across years, therefore data are summarized in the following sets of scatter plots of Importance vs. Ability /Preparation for the full college across all programs and all years. The full text for each question can be found in the appropriate Appendix 1 segment.

Weighting of the scale were as follows: Importance: Not Important $=1$, Somewhat Important $=$ 2 , Important $=3$, Very Important $=4$, Extremely Important $=5$

Ability on the Job or Preparation: Not prepared $=1$, Somewhat Prepared $=2$, Prepared $=3$, Well Prepared $=4$, Very Well Prepared $=5$

Figure 1

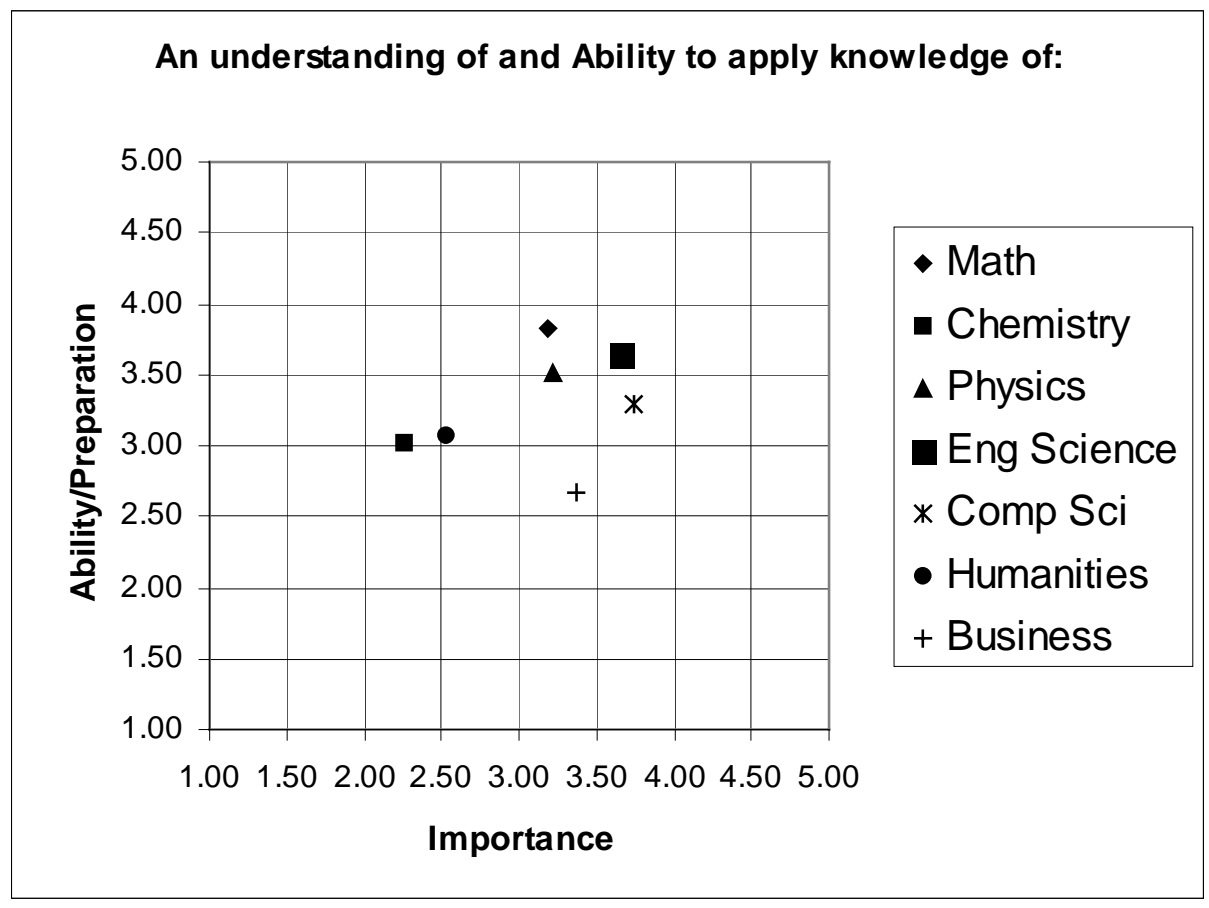


Figure 2

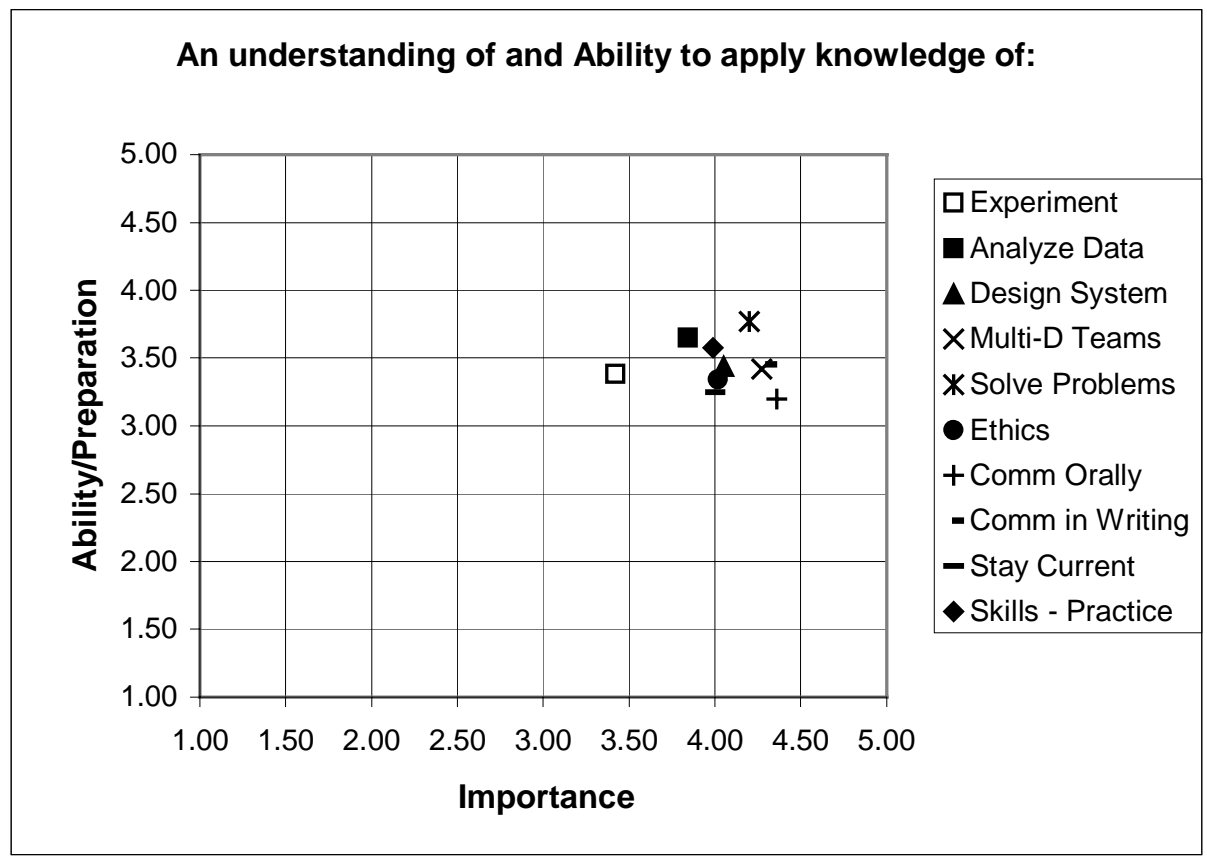

Figure 3

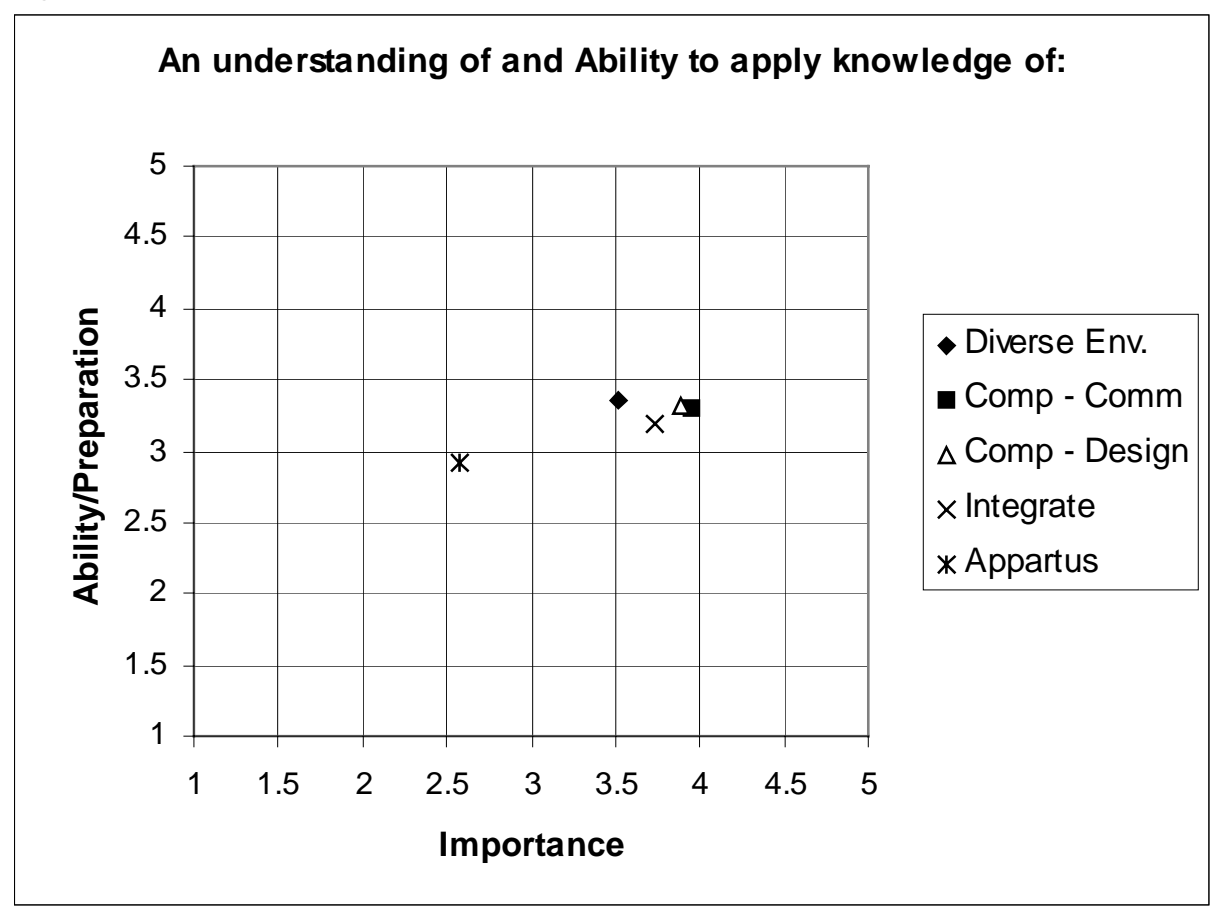


Figure 4

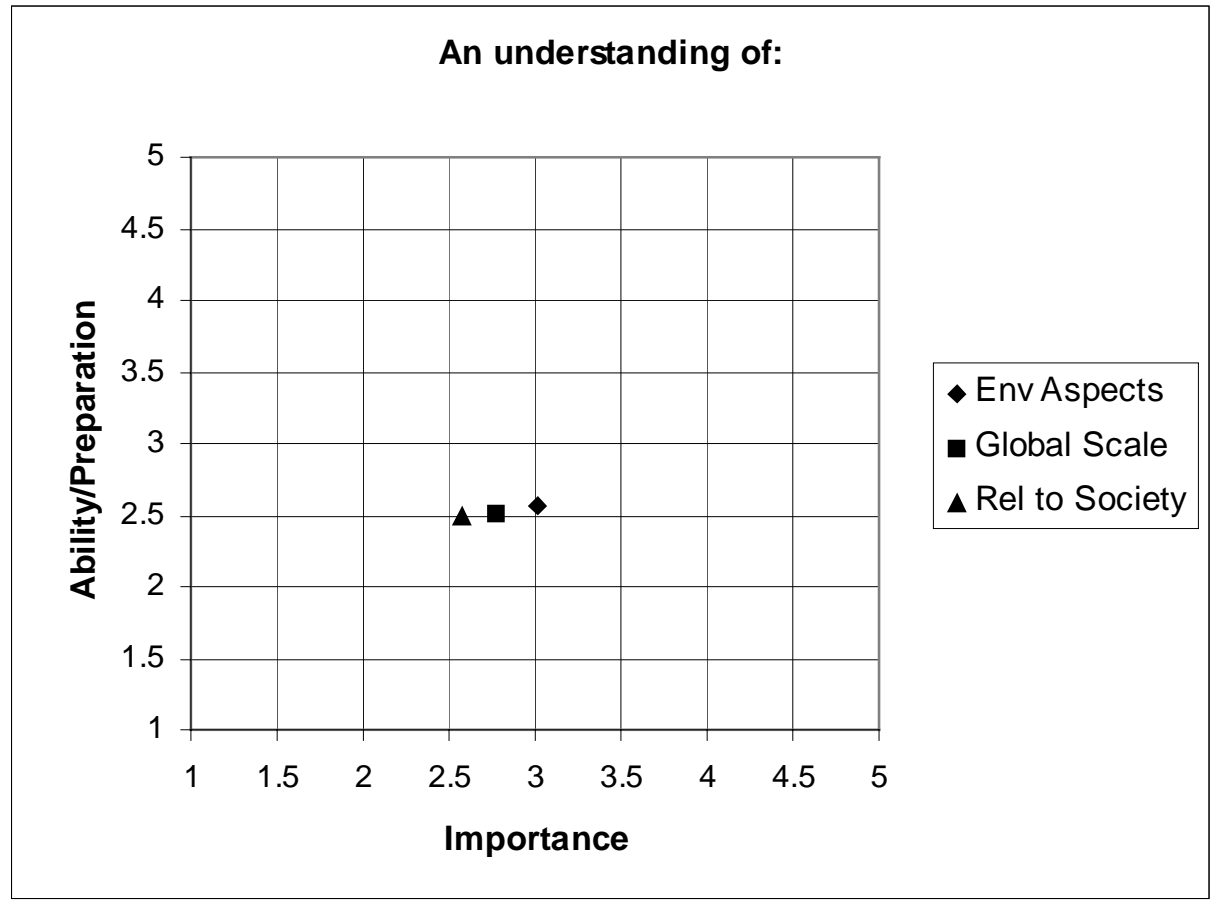

Looking at those items with the largest differences between Importance versus Ability/Preparation, the following six areas were recommended by the OAC for highest priority consideration by the College. In each case some discussion of current activity and preliminary recommendations for action, or continued action, were noted by the committee in its report to the faculty. Each program as well appropriate College committees, were encouraged to review the College summary and those from individual programs to make decisions on their actions.

Reference Question(s)

\section{Ability/Prep. - Importance}

\section{Communications}

An understanding of and ability to:

- communicate orally: informal and prepared talks

- communicate in writing: letters, technical reports, etc.

- use computing technology in communications

Teamwork

An understanding of and ability to:

- function on multi-disciplinary or cross-functional teams $\quad-0.86$

Basic Sciences

An understanding of and ability to apply knowledge of:

- chemistry

- mathematics

Business

An understanding of and ability to apply knowledge of:

- business/finance

Stay Current 
An understanding of and ability to:

- stay current technically and professionally

Ethics

An understanding of and ability to:

- recognize professional and ethical responsibility

\section{Educational Experience at Ohio State - Summary}

Both exiting seniors, Yr-2 and Yr-6 alumni were asked to evaluate selected aspects of their experience at OSU (part III of the Survey). The Table below gives a sample of the results obtained.

Table 2. Sample Educational Experience Results

\begin{tabular}{|c|c|c|c|c|}
\hline & $\begin{array}{c}\text { Exits } \\
\text { Yr } 0 \text { - } 99\end{array}$ & $\begin{array}{c}\text { Alumni } \\
\text { Yr } 2 \text { - } 96\end{array}$ & $\begin{array}{c}\text { Alumni } \\
\text { Yr } 6 \text { - } 92\end{array}$ & Mean \\
\hline \multicolumn{5}{|c|}{ Quality of instruction provided in MAJOR: } \\
\hline Faculty & 4.06 & 4.1 & 4.16 & 4.11 \\
\hline TAs & 3.68 & 3.55 & 3.57 & 3.60 \\
\hline \multicolumn{5}{|c|}{ Quality of Advising with respect to: } \\
\hline Academic & 4.15 & 3.70 & 3.12 & 3.66 \\
\hline \multicolumn{5}{|l|}{ Overall Preparation: } \\
\hline $\mathrm{Be}$ an engineer & 4.06 & 3.98 & 3.99 & 4.01 \\
\hline Obtain $1^{\text {st }}$ job & 4.20 & 4.10 & 3.93 & 4.08 \\
\hline Transition into $1^{\text {st }}$ job & 4.01 & 3.80 & 3.64 & 3.82 \\
\hline Develop Professionally & 4.15 & 3.93 & 3.95 & 4.01 \\
\hline Contribute & 4.25 & 3.99 & 3.96 & 4.07 \\
\hline
\end{tabular}

Although they cannot be shown as cause and effect by this data, changes in value over time in a number of cases correlate to known changes in program. For example, improvement in Science and Engineering Library between the Year 6 (3.61) and Year 2 (4.44) alumni corresponds to opening of a new Science and Engineering Library. Similarly improvement in Computer Labs corresponds to the introduction of the computer fee and corresponding expansion of laboratories. Improvements in Academic Advising also corresponds to the movement of the majority of Premajor advising from University College (a general college of admission) to the College of Engineering.

\section{Additional Comments from Supervisor $\left(15^{\text {th }}\right.$ Year Alumni) Survey}

Forty-seven of the surveys had comments on graduates and twenty-six made suggestions on improving the survey. Each Supervisor Survey with written comments (54) was copied and distributed to each member of the Outcomes Assessment Committee. The comments are summarized in the two tables below. 
Table 3. Most Common Comments on Graduates

\begin{tabular}{|l|c|}
\hline \multicolumn{1}{|c|}{ Comment } & Number of times \\
\hline Communication skills (oral and written) are critical & 12 \\
\hline $\begin{array}{l}\text { Add business courses \& relate to engineering problems (product } \\
\text { liability, environmental concerns, global perspective, safety) }\end{array}$ & 11 \\
\hline $\begin{array}{l}\text { Practical experience/co-op very important/ability to apply knowledge } \\
\text { to real world }\end{array}$ & 10 \\
\hline OSU graduates are well prepared & 10 \\
\hline Ability to work on a multifunctional team is critical & 8 \\
\hline $\begin{array}{l}\text { Have not observed a recent OSU graduate so comments based on } \\
\text { own experience }\end{array}$ & 5 \\
\hline Computer skills critical & 3 \\
\hline Understanding of basics to be prepared for technological changes & \\
\hline
\end{tabular}

Table 4. Comments on Improving the Survey

\begin{tabular}{|l|c|}
\hline \multicolumn{1}{|c|}{ Comment } & Number of times \\
\hline Put survey on web - let people know by mail where it is & 4 \\
\hline Survey is a good start & 3 \\
\hline Make results into a magazine(s) article & 3 \\
\hline Make it more discipline specific & 2 \\
\hline Show that OSU acts upon the suggestions on improving education & 1 \\
\hline Add government service & 1 \\
\hline Ask what degrees are in most demand/what the trends are & 1 \\
\hline Send survey to recruiters/interviewers & 1 \\
\hline Categorize skills & 1 \\
\hline Ask what skills they use on the job & 1 \\
\hline
\end{tabular}

Although comments received have been very useful, the approach of using $15^{\text {th }}$ year alumni as a representative body for supervisors and employers of our students resulted in only a small number of observations, in particular for smaller programs. Either a different approach or summation over multiple years may be needed to get data that is more reliable from this group.

9. OAC Activities and Observations

Upon completion of the first year of surveys, the first responsibility of the OAC was to see that this report is shared widely with programs and committees in the College and colleague units (e.g. Mathematics, Chemistry, Physics, Eng. \& Sci. Library, etc.). Programs are encouraged to share results with their Departmental Advisory Boards. The report was shared with $15^{\text {th }}$ Year alumni requesting a copy of the survey results.

The Committee was very pleased with the information received by asking for the two responses regarding importance and preparation. It was deemed that this approach helps identify and prioritize areas for further study and action. The Committee decided that the surveys should be used for at least one more year, with only minor refinements, before significant changes might be considered. Although results from data aggregated across the College are likely based on large enough number of observations to be meaningful, small numbers of respondents within a particular program may be a constraint to this approach. Use of the survey for multiple years or with multi-year groups may help overcome this difficulty. 


\section{ROBERT J. GUSTAFSON}

Robert Gustafson is Associate Dean for Academic Affairs and Student Services in the College of Engineering and Professor of Food, Agricultural and Biological Engineering at The Ohio State University. Dr. Gustafson is a register professional engineering in Minnesota. Dr. Gustafson received B.S. and M.S. degrees in Agricultural Engineering from the University of Illinois and Ph.D. from Department of Agricultural Engineering at Michigan State University in 1974. He served on the faculty of the University of Minnesota from 1975 to 1987, prior to moving to the Ohio State University.

\section{JOHN A. MERRILL}

John Merrill is Program Manager for the Introduction to Engineering Program, in the Office of Academic Affairs and Student Services at The Ohio State University (OSU). Dr. Merrill received his Ph.D. in Instructional Design and Technology from OSU in 1985. Prior to joining the administrative staff in the College of Engineering, he served as an assessment consultant for the College in its preparation for its ABET review, and for its NSF-funded Gateway Coalition projects. Dr. Merrill's background includes public school teaching, corporate training, and research on university/government contracts. 
Appendix - Alumni Survey

A cover letter from the Department Chair preceded this instruction sheet.

\author{
The Ohio State University \\ Alumni Assessment of Academic Programs \\ Instruction Sheet
}

1. The Engineering Alumni Survey is broken done into five parts. Part I is concerned with Education Outcomes - General, Part II with your Educational Experience at Ohio State, Part III with your major program, Part IV with Additional Comments and Suggestions, and Part V with Background Information.

2. Some questions have multiple parts. All questions relate to your undergraduate education at Ohio State. We estimate that it will take you approximately 15 minutes to complete the survey.

3. The results of this survey will be used to assist us in improving the undergraduate engineering education here at Ohio State. The surveys will be treated as confidential and will only be used in a tabulated form.

4. If you have any comments about the survey beyond those you included in the survey you may send them to:

Edward B. McCaul, Jr., PE

Academic Affairs

College of Engineering

181A Hitchcock Hall

2070 Neil Avenue

Columbus, OH 43210-1278

Phone: 614-292-7931

Fax: 614-688-3805

e-mail: mccaul.1@osu.edu

5. Please return the survey in the enclosed addressed postage paid envelope not later than 15 February 1999. Thank you for your time and cooperation. 


\section{Education Outcomes - General}

Please rate the following skills, abilities, and attributes generally expected of an engineering graduate. First rate how important each has been relative to your needs and employment experience since graduation. Second rate each item relative to your abilities in each area. If a question is not applicable, please leave it blank.

Your Ability on the job

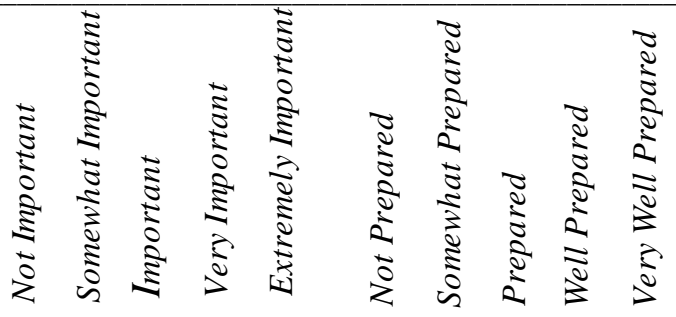

A. An understanding of and ability to apply knowledge of:

1. mathematics (calculus and above)

2. chemistry

3. physics

4. engineering sciences

5. computer science

6. humanities/social sciences

7. business/finance
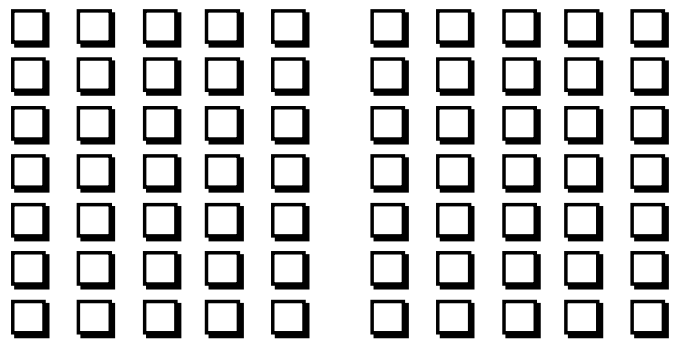

B. An understanding of and ability to:

1. design and conduct experiments

2. analyze and interpret data from experiments

3. design a system, component, or process to meet a desired need

4. function on multi-disciplinary or cross-functional teams

5. identify, formulate, and solve engineering problems

6. recognize professional and ethical responsibility

7. communicate orally: informal and prepared talks

8. communicate in writing: letters, technical reports, etc.

9. stay current technically and professionally

10. use techniques, skills, and tools in engineering practice

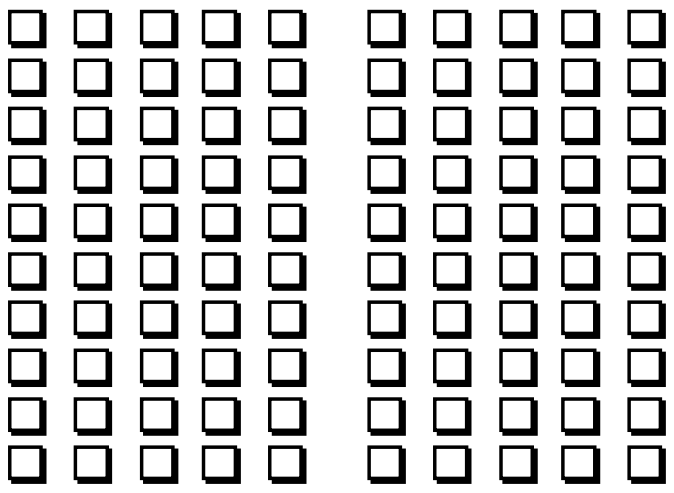

C. An understanding of and ability to:

1. function in culturally and ethnically diverse environments

2. use computing technology in communications

3. use computing technology in engineering analysis/design

4. synthesize and integrate knowledge across disciplines

5. use a wide range of experimental apparatus
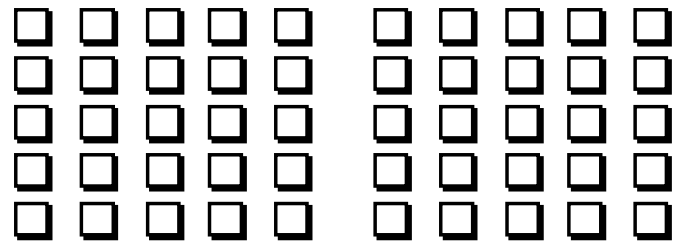

D. An understanding of:

1. environmental aspects of engineering practice

2. the practice of engineering on a global scale

3. the relation of engineering to societal and cultural issues

E. Being a Licensed Professional Engineer and/or Surveyor

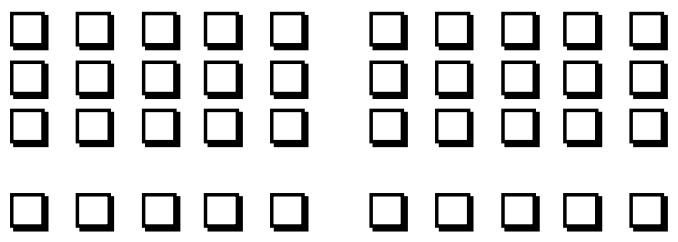




\section{Educational Experience at Ohio State}

Please indicate your evaluation of the following aspects of your experience at OSU

A. The quality of instruction provided in your major:

1. Faculty

2. Teaching Assistants

B. The quality of instruction provided by FACULTY outside your major:

1. Computer Science

2. Engineering Graphics

3. Engineering Mechanics

4. Electrical Engineering

5. Industrial and Systems Engineering

6. Materials Science and Engineering

7. Mechanical Engineering

C. The quality of instruction provided by FACULTY in non-engineering courses:
1. Chemistry
2. Humanities/Social Sciences
3. Mathematics
4. Physics

D. The quality of instruction provided by TEACHING ASSISTANTS in:
1. Chemistry
2. Humanities/Social Sciences
3. Mathematics
4. Physics

E. The quality of advising with respect to:
1. Academic planning
2. Career planning
3. Graduate education
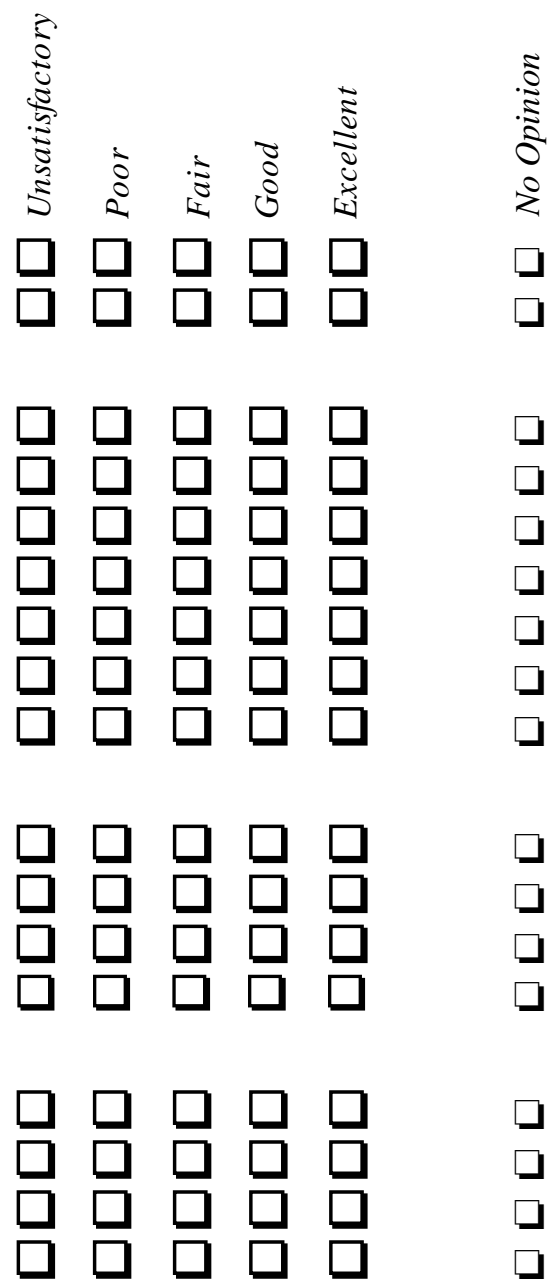

F. The physical quality of the following facilities:

1. Computer Labs

2. Classrooms

3. Science laboratories

4. Engineering laboratories

5. Science and Engineering Library

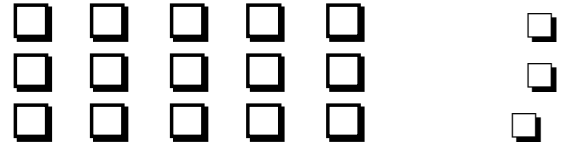

G. How would you rate your overall preparation to:

1. Be an engineer and/or surveyor

2. Obtain your first job after graduation

3. Transition into your first job

4. Develop professionally as an engineer and/or surveyor

5. Contribute to society as a professional

$\square \square \square \square \square$
$\square \square \square \square$
$\square \square \square \square$
$\square \square \square$
$\square \square \square \square$
$\square$

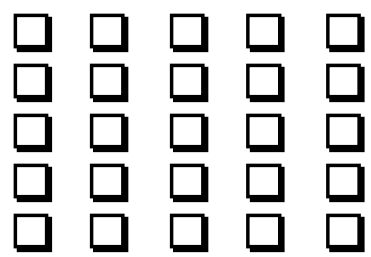

$\square$
$\square$
$\square$
$\square$
$\square$ 


\section{Department Page}

A page designed by the Department/Program was inserted here.

Gender:

$\square$ Female

$\square$ Male
V. Background Information

Racial/Ethnic Group:

$\begin{array}{ll}\square \text { African-American } & \square \text { Native-American } \\ \square \text { Asian-American } & \square \text { Hispanic-American } \\ \square \text { Caucasian } & \square \text { Other }\end{array}$

Present Employment Status: (Please check only one)

$\square$ Employed full-time
$\square$ Caring for family/home full time
seeking employment
$\square$ Other

$\square$ Employed part-time

$\square$ Unemployed, seeking employment $\square$ Serving in the Military

$\square$ Unemployed, not

Are you currently employed as an Engineer/Surveyor $\quad \square$ Yes $\quad \square$ No Year of Graduation (BS Degree) from OSU:

In what program did you receive your degree:

Did you receive a second degree from OSU? $\square$ Yes $\square$ No Indicate program: BS in MS in

Ph.D. in

How many quarters of co-op/internship employment or employment in engineering did you have while a student at OSU? (Check one)

$\square 0$ quarters $\square 1$ - 2 quarters $\square$ 3- 4 quarters $\square$ more than 4 quarters What are your primary job functions (please check no more than three)?

$\begin{array}{llll}\square_{\text {Design }} & \square \text { Manufacturing } & \square \text { Research and Development } & \square \text { Service } \\ \square \text { Sales } & \square \text { Plant Engineer } & \square \text { Project Engineer } & \square \text { Process } \\ \text { Engineer } & \square \text { Computer Applications } & \square \text { Computer Systems Administration } & \square \text { Medical } \\ \square \text { Testing/Reliability } & \square_{\text {Education }}^{\text {Construction }} & \square \text { Sound } \\ \square \text { Purchasing/Procurement } & \square \text { Surveyor } \\ \square \text { GIS/LIS Administrator } & \square \text { Hydrographic Surveyor } & \square \text { Management } & \square \text { Consultant } \\ \square \text { Other } & & \end{array}$

Which of the following is applicable to you? (Check all that apply)

Passed the Fundamentals Examination (formally known as the EIT/SIT)

Engineer

$\square$ Have attended a professional/technical society conference(s)

graduate degree

$\square$ Have participated in continuing education other than graduate school professional

$\square$ Licensed Professional Surveyor $\square$ Licensed Professional

$\square$ Have pursued studies toward a

Member of a technical or

organization/society

Since receiving your bachelor's degree from Ohio State, have you worked outside of the United States as an engineer and/or surveyor?

$\square$ Yes $\square$ No

While completing your bachelor's degree at Ohio State, were you a U.S. citizen? $\square$ Yes $\square$ No 